\title{
Uma revisão sobre o vírus da dengue e seus vetores
}

\author{
A review of dengue virus and its vectors \\ Una revisión del virus del dengue y sus vectores
}

Recebido: 26/07/2021 | Revisado: 31/07/2021 | Aceito: 06/08/2021 | Publicado: 10/08/2021

\author{
Adriano José de Barros \\ ORCID: https://orcid.org/0000-0003-4199-4999 \\ Pontifícia Universidade Católica de Minas Gerais, Brasil \\ E-mail: adrianojosebarros@yahoo.com.br \\ Sandro Linhares \\ ORCID: https://orcid.org/0000-0001-8873-695X \\ Pontifícia Universidade Católica de Minas Gerais, Brasil \\ E-mail: sandrolaudares@gmail.com \\ Ediene Monteiro Romão \\ ORCID: https://orcid.org/0000-0002-3413-0423 \\ Universidade de São Paulo, Brasil \\ E-mail: edieneromao@usp.br \\ Aurilaine Ávila de Freitas \\ ORCID: https://orcid.org/0000-0003-1882-473X \\ Universidade do Estado de Minas Gerais, Brasil \\ E-mail: aurilainefreitas@yahoo.com.br \\ Dimária Aparecida Fernandes Dias \\ ORCID: https://orcid.org/0000-0002-9391-7875 \\ Universidade Federal de Itajubá, Brasil \\ E-mail: dimariafernandesagro@gmail.com \\ Graziele Viegas \\ ORCID: https://orcid.org/0000-0002-8280-8729 \\ Universidade do Estado de Minas Gerais, Brasil \\ E-mail: grazy.viegas@yahoo.com.br
}

\begin{abstract}
Resumo
Os primeiros relatos de uma doença com prognósticos clínicos semelhantes no ser humano aos da dengue estão relatados na Enciclopédia Médica Chinesa da Dinastia Jin (265-420 AD). A doença é endêmica em países da África, Américas, Ásia, Caribe e Pacífico. A dengue é considerada uma enfermidade viral reemergente, com uma estimativa de quase 400 milhões de novas infecções por dengue por ano no mundo. Na atualidade a dengue atinge bilhões de pessoas que habitam em áreas de risco de infecção apresentando manifestações clínicas, como febre, erupção cutânea, dor ocular e hemorragia. A dengue é motivo de preocupação sanitária e ambiental em inúmeros países mundo, particularmente em países tropicais e subtropicais onde os mosquitos vetores Aedes aegypti e Aedes albopictus estão existentes no meio ambiente destas localidades. A transmissão desse vírus no ser humano, é conhecida como transmissão horizontal, dá-se através da picada de fêmeas infectadas de uma ou outra das duas espécies de mosquitos. No presente artigo, foi realizada uma pesquisa bibliográfica para compreensão e análise do objeto de estudo em artigos científicos e normas técnicas. A caracterização da transmissão e sintomas da dengue é de suma importância para a implementação ideal de novos programas de controle e prevenção de políticas públicas na sociedade, incluindo campanhas de controle junto à sociedade. Fornecendo descrição que possam auxiliar no combate da transmissão da dengue e na preparação para resposta a surtos e permitir a detecção precoce de notificações e respostas atempada nas áreas de incidência de dengue.
\end{abstract}

Palavras-chave: Aedes aegypti; Aedes albopictus; Transmissão; Sintomas; Meios de detecção.

\begin{abstract}
The first reports of a disease with similar clinical prognoses in humans to dengue are reported in the Chinese Medical Encyclopedia of the Jin Dynasty (265-420 AD). The disease is endemic in countries in Africa, the Americas, Asia, the Caribbean and the Pacific. Dengue is considered a re-emerging viral disease, with an estimated nearly 400 million new dengue infections per year worldwide. Currently, dengue affects billions of people who live in areas at risk of infection with clinical manifestations such as fever, rash, eye pain and hemorrhage. Dengue is a matter of sanitary and environmental concern in many countries around the world, particularly in tropical and subtropical countries where the vector mosquitoes Aedes aegypti and Aedes albopictus are present in the environment of these locations. The transmission of this virus in humans, known as horizontal transmission, occurs through the bite of infected females of one or the other of the two species of mosquitoes. In this article, a bibliographical research was carried out to understand and analyze the object of study in scientific articles and technical standards. The characterization of dengue
\end{abstract}


transmission and symptoms is of paramount importance for the ideal implementation of new control and prevention programs for public policies in society, including control campaigns in society. Providing descriptions that can help combat dengue transmission and prepare for outbreak response and allow early detection of notifications and timely responses in areas of dengue incidence.

Keywords: Aedes aegypti vectors; Aedes albopictus; Streaming; Symptoms; Means of detection.

\section{Resumen}

Los primeros informes de una enfermedad con un pronóstico clínico similar en humanos al dengue se publican en la Enciclopedia Médica China de la Dinastía Jin (265-420 d.C.). La enfermedad es endémica en países de África, América, Asia, el Caribe y el Pacífico. El dengue se considera una enfermedad viral reemergente, con un estimado de casi 400 millones de nuevas infecciones de dengue por año en todo el mundo. Actualmente, el dengue afecta a miles de millones de personas que viven en áreas de riesgo de infección con manifestaciones clínicas como fiebre, erupción cutánea, dolor ocular y hemorragia. El dengue es motivo de preocupación sanitaria y ambiental en muchos países de todo el mundo, particularmente en los países tropicales y subtropicales donde los mosquitos vectores Aedes aegypti y Aedes albopictus están presentes en el medio ambiente de estos lugares. La transmisión de este virus en humanos, conocida como transmisión horizontal, se produce por la picadura de hembras infectadas de una u otra de las dos especies de mosquitos. En este artículo se realizó una investigación bibliográfica para comprender y analizar el objeto de estudio en artículos científicos y normas técnicas. La caracterización de la transmisión y los síntomas del dengue es de suma importancia para la implementación ideal de nuevos programas de control y prevención de las políticas públicas en la sociedad, incluidas las campañas de control en la sociedad. Proporcionar descripciones que pueden ayudar a combatir la transmisión del dengue y prepararse para la respuesta a un brote y permitir la detección temprana de notificaciones y respuestas oportunas en áreas de incidencia de dengue.

Palabras clave: Vectores Aedes aegypti; Aedes albopictus; Transmisión; Síntomas; Medios de detección.

\section{Introdução}

Mais de um terço da população do planeta Terra habita áreas tropicais e subtropicais, sendo que estes estão sob risco de infecções pelos sorotipos da dengue, proveniente dos vetores Aedes aegypti e Aedes albopictus, milhões de pessoas são infectadas anualmente por estes vetores trazendo contratempos de ordem social e econômica e principalmente de saúde. Essa doença ressurgiu nos últimos 20 anos na forma de uma epidemia. A dengue é causada por um dos cinco sorotipos relacionados do vírus da dengue sendo que no território brasileiro há notificações dos sorotipos DENV-1, DENV-2, DENV-3 e DENV-4 que geralmente levam a formas graves da doença, devido a infecções secundárias do vírus. O vírus da dengue é um vírus transmitido por mosquitos, da família Flaviviridae e consiste em um genoma de RNA.

Neste contexto, o objetivo da pesquisa é realizar uma revisão bibliográfica sobre o Vírus da Dengue e seus vetores, além de elucidar conceitos sobre a morfologia do mosquito, suas características e hábitos que possuem de sobrevivência.

\section{Metodologia}

Trata-se de um estudo qualitativo e descritivo, do tipo relato de experiência, relatando o histórico da dengue e as características de desenvolvimento do mosquito.

O estudo que se utiliza de uma abordagem qualitativa se refere àquele que apresenta a apreciação do pesquisador, trazendo consigo os subsídios do mesmo sobre a problemática do estudo. Relacionado a isso, esse tipo de pesquisa expõe algumas particularidades como, por exemplo, o investigador é de fundamental significância dentro dessa metodologia; a coleta de informações são preferencialmente descritivas; as concepções que as pessoas dão as coisas e a tudo ao seu redor são de extrema relevância para o investigador; a inquietude da pesquisa se sobrepõe sobre o resultado e ponderações dos dados alcançados inclinam-se a conduzir um processo indutivo (Martins et al., 2021).

Nesta pesquisa é realizada uma revisão da literatura dos vetores já mencionados, seu ciclo de desenvolvimento, a transmissão natural do vírus da Dengue em Aedes aegypti e Aedes albopictus e sintomas da Dengue Clássica e Hemorrágica e os meios de detecção da doença nos seres humanos. As buscas de informações foram realizadas nas normas técnicas do 
Ministério da Saúde, Fiocruz e Organização Mundial de Saúde e em publicações da revista digital SciELO, que foram lidos, analisados e organizados.

Este estudo, resultante de uma revisão bibliográfica, está dividido em quatro tópicos, os quais serão descritos a seguir. Sendo eles: Discussões do Desenvolvimento Teórico; Composição do Vírus da Dengue; Transmissão e Sintomas do Vírus; Diagnóstico e Tratamento da Dengue.

\section{Discussões do Desenvolvimento Teórico}

Segundo Rezende (2021) as arboviroses, a exemplo da dengue, ocasionam um grande impacto na saúde pública que vão desde a identificação do agente causador até as medidas de controle dos vetores. Assim, ressalta-se a importância do saneamento básico como método de controle da incidência e prevalência das infecções por arbovírus. Como também, a detecção de doenças emergentes e reemergentes nos municípios. Portanto, são necessárias pesquisas relacionadas ao entendimento dos ciclos de transmissibilidade urbana e ofertar uma intervenção de forma estratégica para contribuir no seu controle e impedir a urbanização vetorial futura.

Quando indagamos a respeito da Dengue, temos a evidência da contaminação através de vetores e associamos ao gênero Aedes, que possui inúmeras espécies na cadeia biológica. Contudo, apenas três espécies são destaques, na associação com de transmissão da enfermidade: o Aedes albopictus, o Aedes aegypti e o Aedes polynesiensis, espécies eficazes como vetores da dengue.

Os dois primeiros vetores são classificados por (Brasil, 2001), pertencentes ao reino Arthropoda, associados à classe Hexapoda, da ordem Diptera, da família Culicidae, e da subfamília Culicinae, tribo Aedini, do gênero Aedes, sub gênero Stegomyia. As duas espécies apresentam formas equivalente se distinguem pela forma do desenho nas costas de cada um dos mosquitos. O Aedes aegypti tem listras brancas no dorso que se identificam com a forma de uma lira, enquanto o Aedes albopictus apresenta um risco longitudinal no dorso. Já o Aedes polynesiensis é um vetor da dengue encontrado na Polinésia, nos arquipélagos Austrais, Fiji, Pitcairn. Morfologicamente é bastante similar ao Aedes albopictus sendo sua presença não detectada no território Americano. Na Figura 1, é ilustrada a diferença de anatomia do Aedes aegypti e Aedes albopictus.

Figura 1. Diferença Aedes aegypti Vs Aedes albopictus.

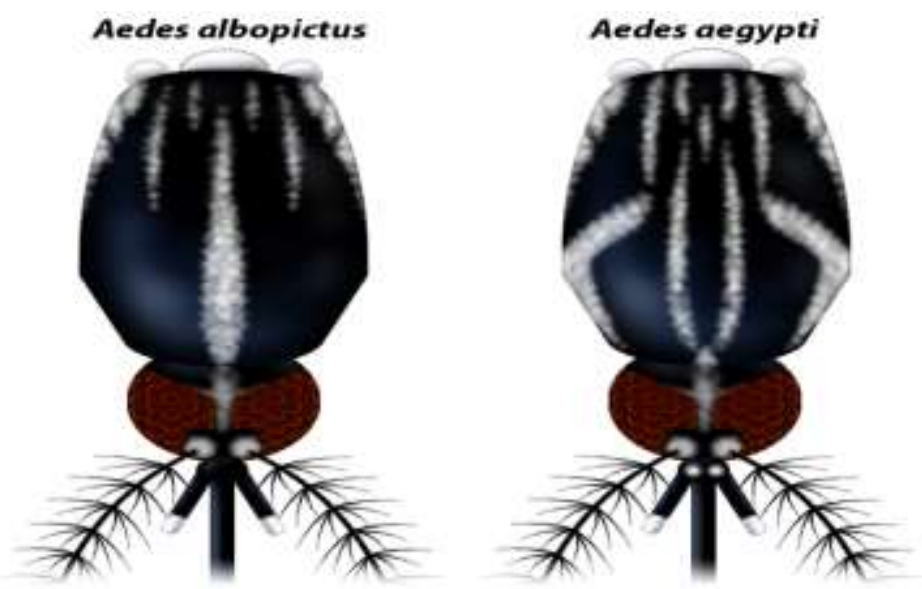

Fonte: Planeta Invertebrados (2021).

As duas espécies possuem hábitos totalmente diferentes, o vetor Aedes aegypti habita de preferência áreas urbanas como o interior das residências e dos imóveis, próximo ao homem. O vetor Aedes albopictus habita ambientes com vegetação robusta como parques e matas. Este contraste demostrado no habito destes vetores, ampara, a "má-fama" do vetor Aedes 
aegypti. Diretamente ligado ao fato da sua preferência de permanecer próximo aos seres humanos, sendo o vetor correlacionado por grande parte dos casos de transmissão da dengue. Assim, há uma constatação que o denominado Aedes albopictus é classificado como um vetor secundário como descrito pelo Instituto Oswaldo Cruz.

Entretanto, o Ae. albopictus tem sido considerado um vetor secundário do vírus da dengue, pois este apresenta em sua estrutura características morfológicas semelhantes e a mesma capacidade de proliferação do Ae. aegypti (Instituto Oswaldo Cruz, 2008).

Há uma correlação entre o vetor Aedes albopictus e sua importância junto à proliferação de enfermidades como a dengue e a febre amarela, embora este vetor seja considerando um vetor secundário, ele exprime uma grande atenção na saúde pública brasileira pela sua disseminação no Brasil. Entretanto, não existem registros da presença do vírus da dengue nestes seres adultos e sim na capacidade de transmissão para sua procriação, segundo o Instituto Oswaldo Cruz (2008).

A dimensão do ovo do Aedes albopictus e de aproximadamente $1 \mathrm{~mm}$. Suportam extensos períodos de estiagem, aproximadamente 243 dias sem deterioração. Em contato com a água as larvas eclodem em seguida. O ovo do vetor apresenta uma cor negra, possui pequenas projeções em forma de grão ao redor da estrutura (FUNASA, 2001). Na Figura 2 é apresentado o ovo do Aedes albopictus.

Figura 2. Ovo do Aedes albopictus.

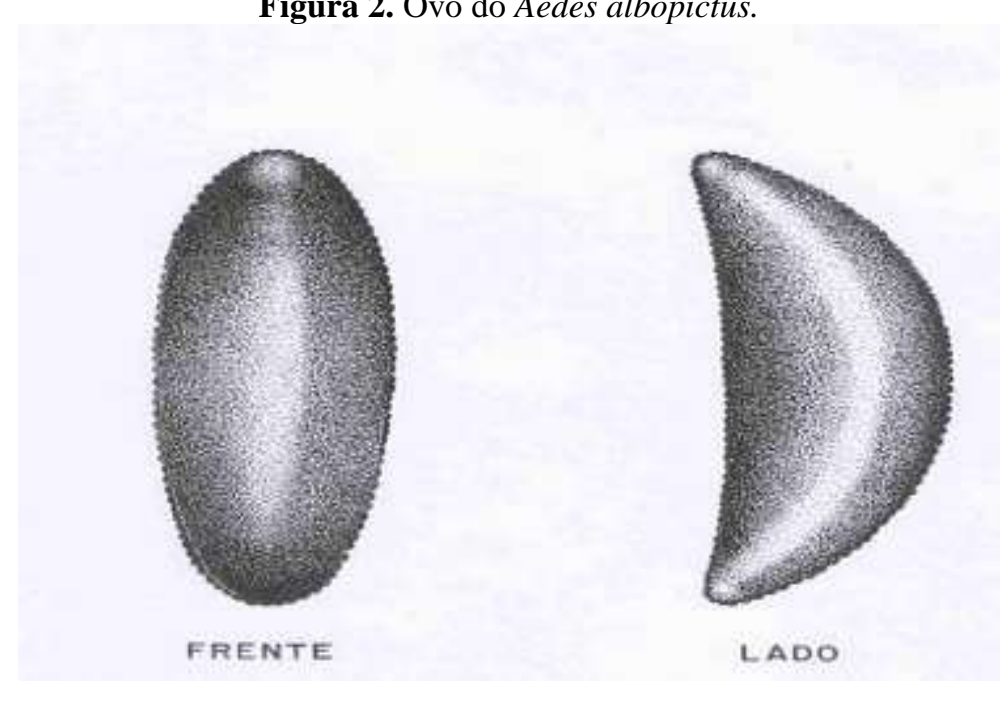

Fonte: Superintendência de vigilância em saúde/Santa Catarina (2015).

As larvas do Aedes albopictus vivem em água, possuem como fonte de nutrição microrganismos e têm grande sensibilidade a luz denominada fotofobia. Apresenta quatro estágios de desenvolvimento que são de 5 a 10 dias, que evoluem para pupa que tem a forma de vírgula (Figura 3) sua estrutura se divide em cefalotårax e abdômen em sua estrutura para respiração há um par de trompetas respiratórias no cefalotårax que atravessa a lâmina de água para respirar. Esta pupa evolui para fase adulta em aproximadamente em 48 horas. 
Figura 3. Pupa do Aedes albopictus

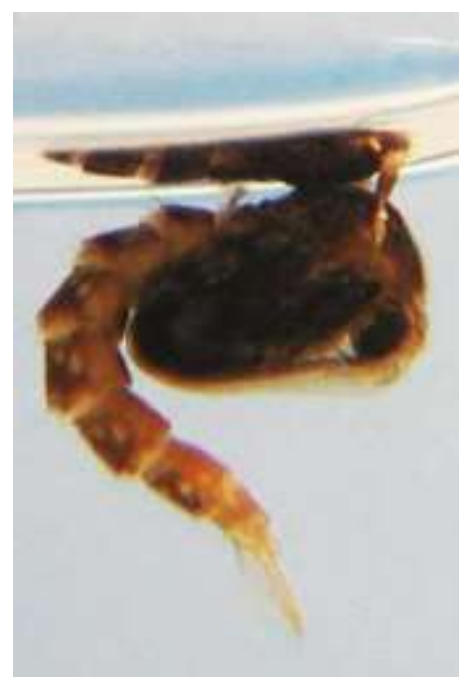

Fonte: Florianiano (2018).

Curiosamente os machos surgem primeiro que as fêmeas. Sendo que a fonte primária de alimentação são o sangue de animais como bois e porcos e aves, os humanos são caracterizados como fontes secundárias de alimentação. Apresenta uma autonomia de voo de correspondente a 200 metros do seu tempo de vida e de 45 a 50 dias, segundo estudos a fêmea ovipa cerca de 950 ovos na sua existência. (FUNASA, 2001).

A morfologia do vetor Aedes aegypti, já apresenta diferenças do Aedes albopictus, primeiramente temos os ovos que no momento da postura, apresentam uma cor esbranquiçada e posteriormente após o contado com o oxigênio, apresentam um marrom ao um escuro brilhante onde também exibido, desenhos alongados e com as extremidades mais estreitas que o centro; seu tamanho possui uma variação entre 0,6 a 0,7mm, os ovos após depositados tem como característica, suportar um vasto período de aridez que perdura aproximadamente 18 meses sem apresentar deterioração em sua infraestrutura (FUNASA, 2001). A Figura 4 apresenta o ovo do Aedes aegypti.

Figura 4. Ovo do Aedes Aegypti.

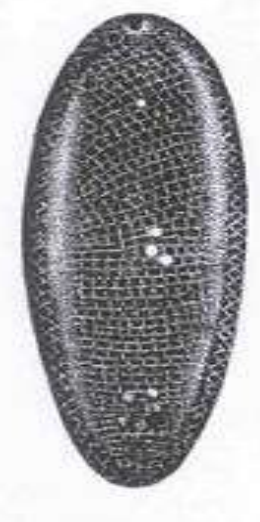

FRENTE

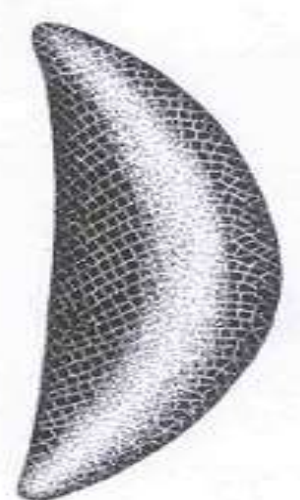

LADO

Fonte: Superintendência de vigilância em saúde/Santa Catarina (2015).

As larvas do vetor Aedes aegypti possui quatro estágios ou ciclos, se alimentam de partículas orgânicas e não perseveram por um prolongado período sem alimentação, também apresentam fotofobia, a estrutura da larva é dividida em 
cabeça tórax e abdômen. No abdômen há um sifão respiratório onde a larva se desloca até a superfície da lâmina de água, seu movimento na água é similar a uma serpente, as movimentações ríspidas na água ou a incidência de luz fazem com que a larva procure abrigo no fundo da estrutura.

A Pupa do vetor Aedes aegypti não se alimenta no seu período de pupa, extraindo energia do seu período larvário, tem como estrutura básica uma divisão em cefalotórax subdividida em cabeça, tórax e abdômen, sua disposição também é apresentada em forma de uma vírgula, como apresentado na Figura 5. Seguidamente entre 2 ou 3 dias a pupa se desponta como vetor adulto.

Figura 5. Pupa do Aedes aegypti.

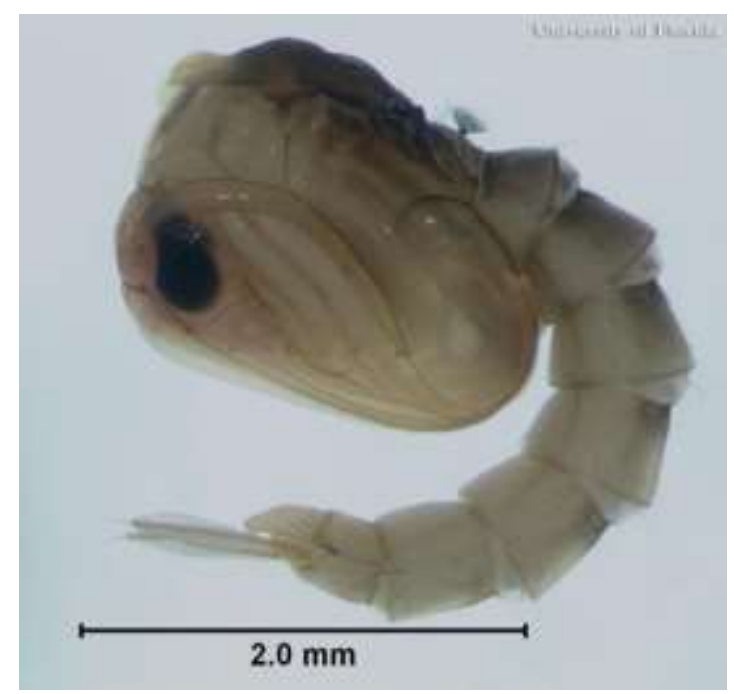

Fonte: De olho no Aedes aegypti (2021).

O vetor necessita de um tempo, para desenvolver seu exoesqueleto e as asas, normalmente 24 horas após este período ele está hábil a voar e se acasalar, apresentando tamanhos diferentes no gênero, Figura 6. Os machos Aedes aegypti, tem sua alimentação baseada em néctar e seiva, as fêmeas do vetor têm como regra se alimentar de sangue, com preferência ao humano, o provimento desse sangue proporciona as proteínas necessárias para maturação dos ovos que, geralmente, estão em locais caracterizados como recipientes naturais: bromélias, buracos em árvores, escavação em rocha, bambu e folhas secas, e em recipientes artificiais: baldes, caixas de água, calhas, restos de lixos, a exemplo de copos de plásticos. Sua predisposição é se adequar ao local da sua gênese, a fêmea possui uma autonomia de voo de1000 metros e tem um ciclo de vida de 30 a 35 dias, tem uma propensão de depositar uma média origem a 1.500 mosquitos no seu tempo de vida que são alocados em diversos criadouros (FUNASA, 2001). 
Figura 6. Diferenças entre a fêmea e o macho do mosquito Aedes aegypti.

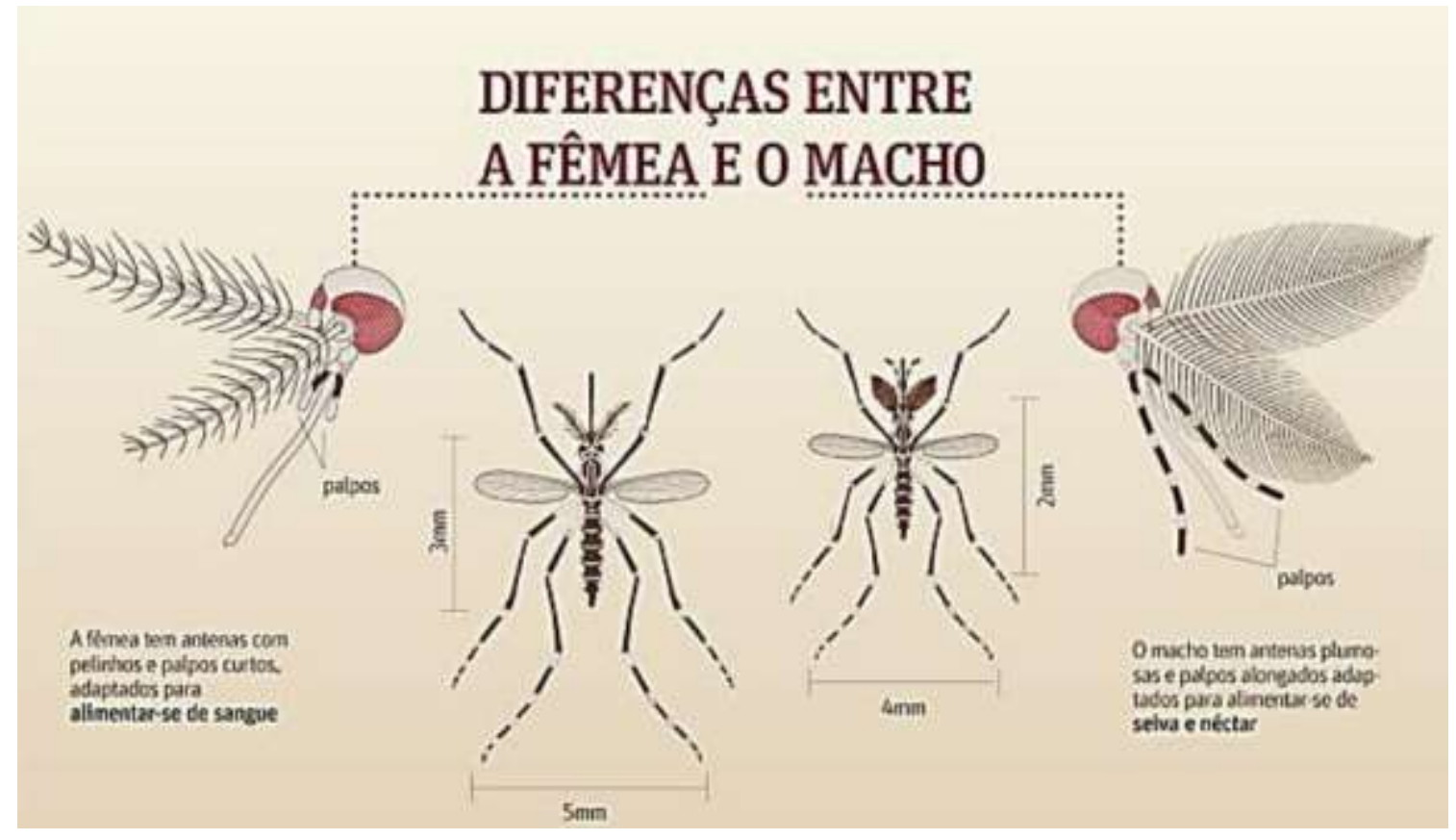

Fonte: Marques (2018).

Como visualizado na Figura 6, a estrutura corporal do vetor fêmea do Aedes aegypti possui $1 \mathrm{~mm}$ de altura e comprimento superior ao vetor macho, somado a este coeficiente temos as diferenças nas antenas em que a fêmea apresenta palpos curtos para extração de sangue diferentemente do macho que possui palpos alongados adaptados para se nutrir de seiva e néctar natural.

A transmissibilidade viral exercida pelos vetores pode ser influenciada por uma junção de elementos que incluem fatores externos: temperatura, mudança climática, chuvas, e internos: imunidade, genética, expectativa de vida. A temperatura, principalmente, tem um papel importante, devido aos insetos vetores serem sensíveis às mudanças de temperatura (Samuel, et al., 2016).

Diante ao exposto da não existência de ocorrências de dengue em seres humanos pelo Aedes albopictus no território brasileiro, a pesquisa terá como foco o vetor Aedes aegypti como vetor principal de transmissão (Catão, 2012).

\section{Composição do Vírus da Dengue}

O vírus da dengue é denominado uma arbovirose, vírus que é principalmente propagado por artrópodes, a palavra arbovírus se origina da locução inglesa ARthropod BOrne VIRUSES, de 1942, para denominar a categoria de infecções virais cujos agentes foram identificados e isolados de animais que tinham participação na etiologia das encefalites. Os arbovírus acentuam-se nos tecidos dos organismos dos artrópodes, que se tornam vetores depois de sugarem sangue de hospedeiros na temporada relativa à viremia, presença do vírus no homem. Período que se inicia um dia antes do surgimento da febre e se prolonga até o sexto dia da doença. Já a família do vírus é a Flaviviridae, constituída por três gêneros: Flavivirus, Pestivirus e Hepacivirus. O gênero Flavivirus abrange cerca de 39 variedades que são classificadas como arbovírus, pertencendo algumas geradoras de febres hemorrágicas em humanos e animais. Evidenciando neste cenário o vírus dengue e o da febre amarela. (Lopes et $a l, 2014)$. Na Figura 7 é ilustrado o vírus da dengue em célula infectada ao microscópio eletrônico. 
Figura 7. Vírus da dengue em célula infectada ao microscópio eletrônico.

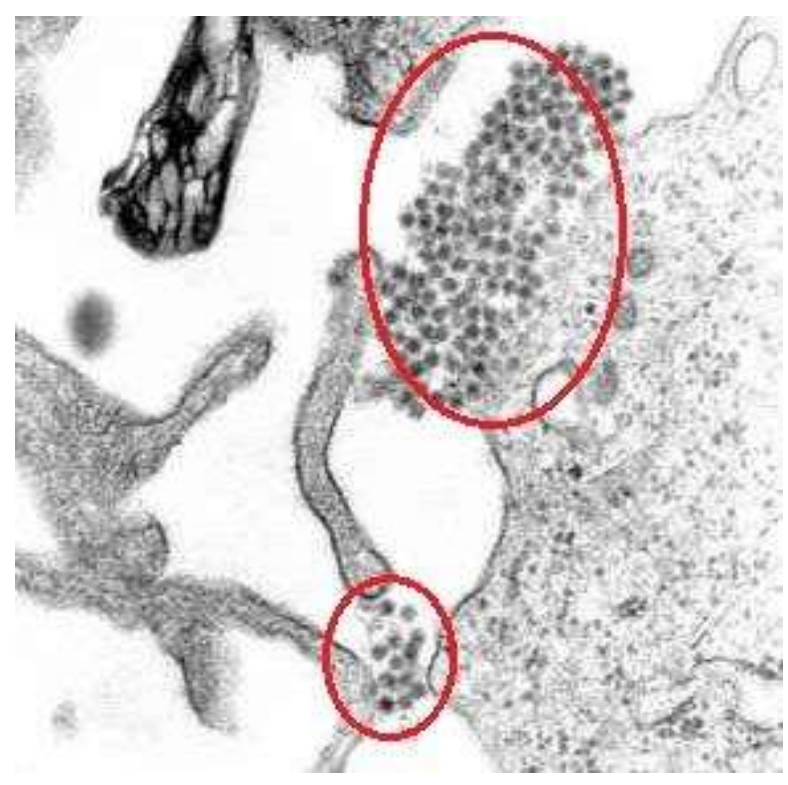

Fonte: Fiocruz (2021).

O vírus dengue (DENV) é retratado por quatro sorotipos, DENV-1, DENV-2, DENV-3 e DENV-4. O relato de mais de um sorotipo, DENV-1 e DENV-2, decorreu por volta de 1940, e o DENV-3 e o DENV-4 foram isolados inicialmente no decorrer das epidemias nas Filipinas em 1956 ainda há o tipo 5 DENV-5, identificado em 2007 na Malásia no continente Asiático, sem ocorrências no Brasil (Barreto \& Teixeira, 2008)

A diferença é baseada em reações de anticorpos contra antígenos de superfície no vírus. Cada sorotipo tem diferenças sutis em suas proteínas de superfície, o que significa que diferentes anticorpos são produzidos para se ligar a essas proteínas.

\section{Transmissão e Sintomas do Vírus}

Raramente a proliferação dos vetores acontece em temperaturas abaixo de $16^{\circ} \mathrm{C}$, as condições mais adequadas para a transmissão ocorrem em temperaturas entre $30^{\circ}$ a $32^{\circ} \mathrm{C}$, sendo assim, há uma grande incidência do desenvolvimento do vetor nas áreas tropicais e subtropicais do planeta (Viana \& Ignotti, 2013)

A transmissão da doença tem sua gênese a partir momento em que o vetor pica um ser humano infectado por um dos quatro sorotipos da dengue, o mosquito vetor passa assim a se apto a disseminar o vírus depois de 8 a 12 dias de incubação outra forma seria através de sangue contaminado por transfusão de sangue.

Indagador da transmissão do vírus está no processo, onde o mosquito simultaneamente ao picar o ser humano, expele uma substancia que contém propriedades analgésicas e anticoagulantes, que tem como princípio ajudar o vetor a ficar imperceptível durante o processo, Figura 8 (Viana \& Ignotti, 2013).

Após a inserção do vírus no corpo humano, o vírus começa a infectar as células imunes da pele, penetrando no sistema linfático, podendo gerar uma reação inflamatória, durante o período de incubação o vírus se multiplica localmente, posteriormente, se dissemina pelo sangue da pessoa infectada. 
Figura 8. Esquema de alimentação do Aedes aegypti.

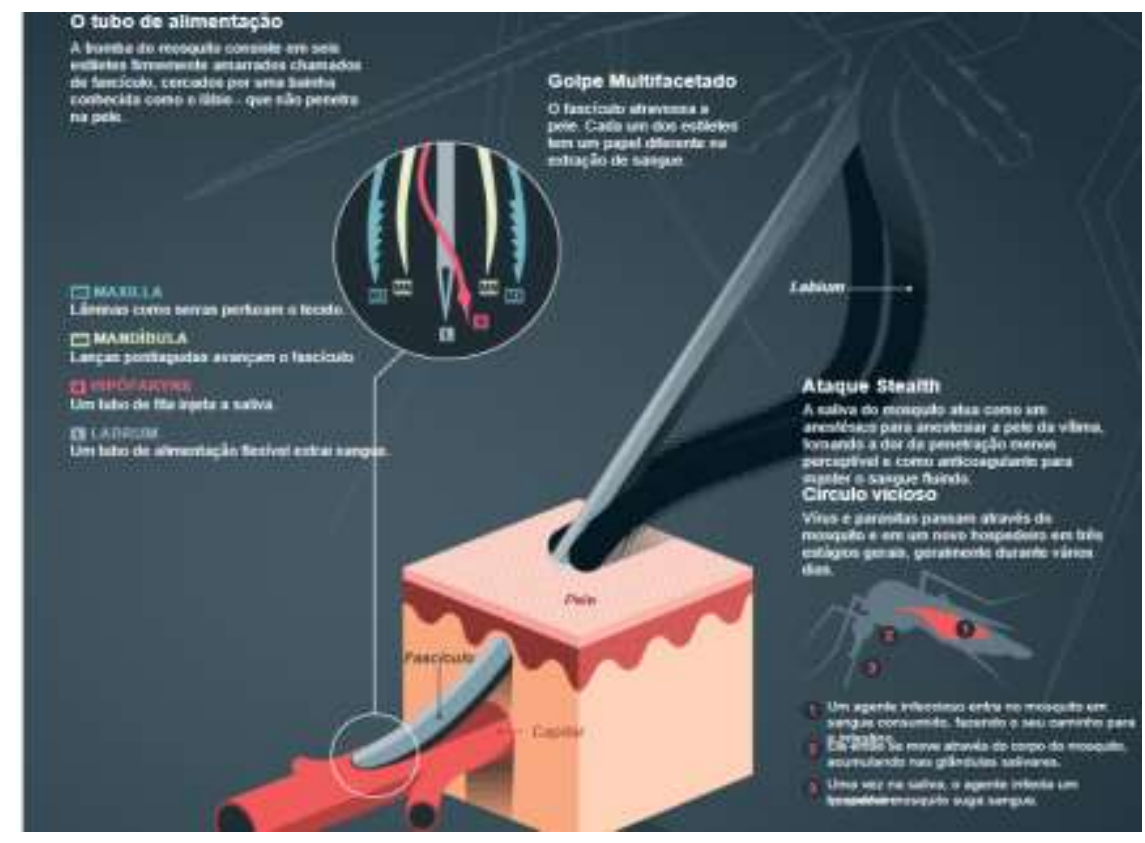

Fonte: National Geographic (2019).

Em seu aspecto clássico, a dengue é uma doença aguda descrita com sintomas clássicos como, febre, dor de cabeça, dores musculares e articulares e erupção cutânea (Figura 9) no corpo com manchas vermelhas na pele que podem lembrar a rubéola associado a uma coceira e uma dor abdominal, sobretudo em crianças, falta de apetite e fraqueza no corpo estes sintomas de modo geral duram até uma semana. (Singhi et al, 2007).

Figura 9. Erupção maculopapulosa morbiliforme localizada no tórax.

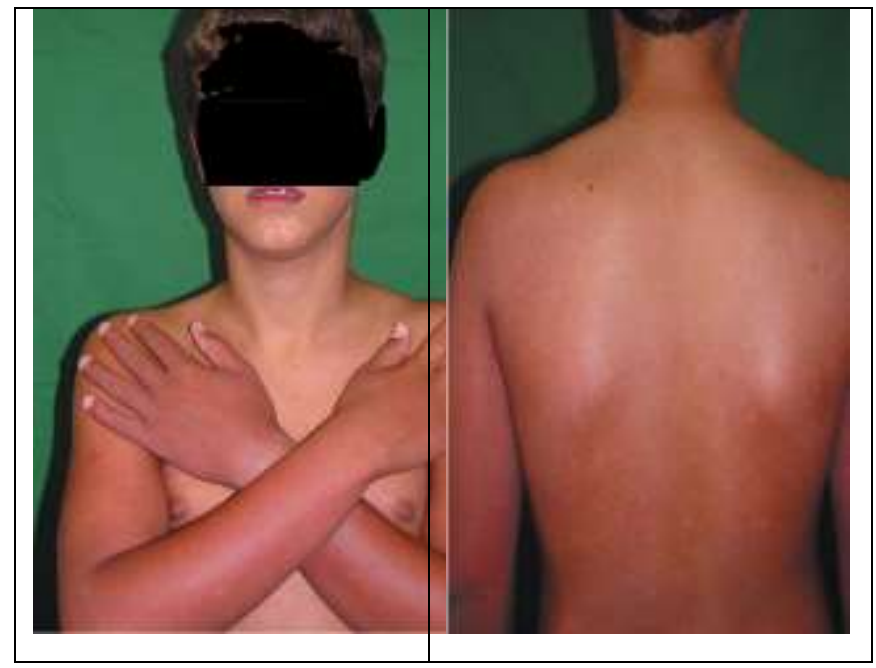

Fonte: Paulo Sérgio Emerich, adaptado de Barros (2021).

A imunidade contra um sorotipo específico é vitalícia, mas a infecção antecedente com um sorotipo é um elemento de risco para um contágio mais grave de dengue a denominada febre hemorrágica da dengue, após infecção subsequente com um sorotipo diferente. A febre hemorrágica do dengue é mais preocupante, identificada pela síndrome de vazamento capilar, trombocitopenia, hemorragia, hipotensão e choque de febre (OMS, 2019)

Contudo, a dengue hemorrágica apresenta alguns sinais de alerta que podem ser pautados como dores abdominais fortes e contínuas, vômitos persistentes, pele pálida, fria e úmida, sangramento pelo nariz, boca e gengivas, manchas vermelhas 
na pele, ainda apresentado quadros de sonolência, confusão mental, dificuldade respiratória, por fim pode haver perda de consciência com evolução para a morte, o quadro clínico final pode se agravar em até vinte e quadro horas (OMS, 2019). Os diagnósticos dos sintomas da dengue clássica e hemorrágica podem ser apontados na Figura 10.

Figura 10. Sintomas da dengue clássica e hemorrágica.

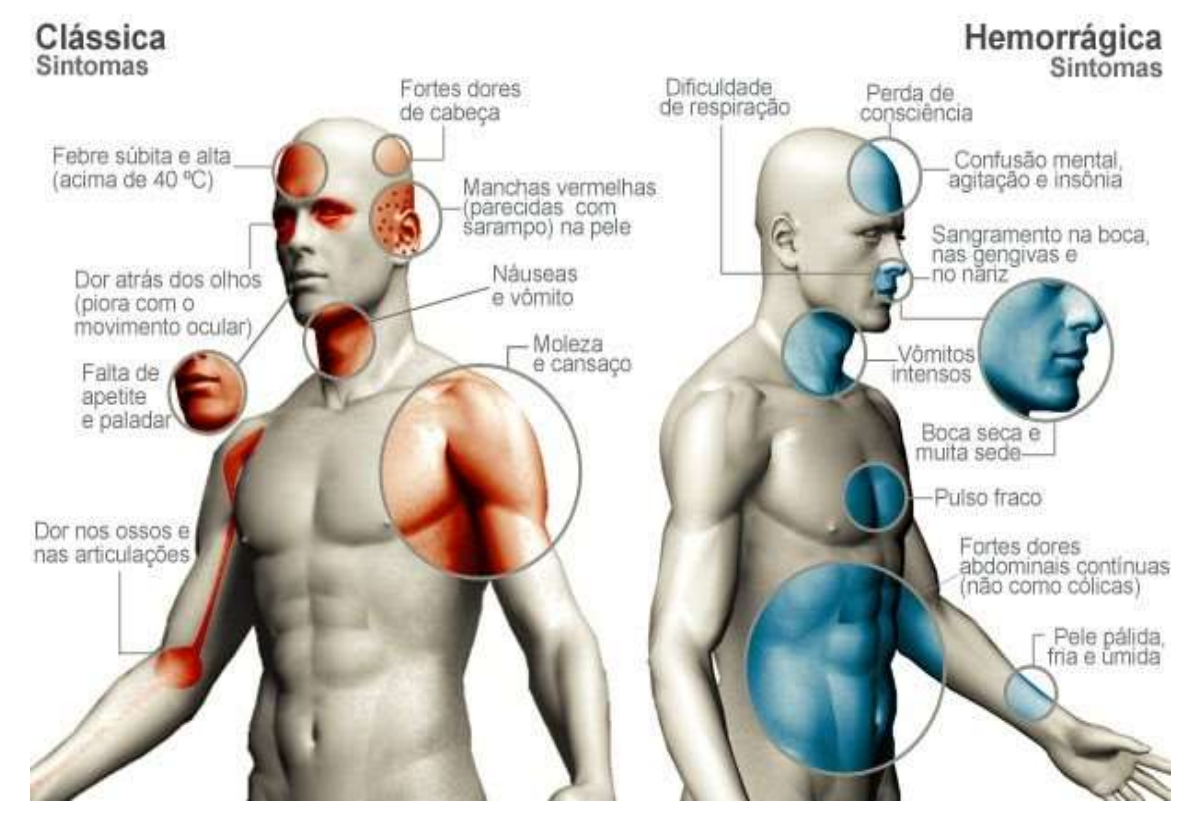

Fonte: Portal de notícias Globo (2019).

Qualificando primordialidade da participação dos profissionais da saúde de forma multidisciplinar, no diagnóstico e no auxilio no atendimento da dengue e suas condições no ser humano a categorização clínica e respaldada em doados laboratoriais e prognósticos clínicos por profissional que tenham competências e habilidades na classificação da dengue conforme a sua gravidade. Desta forma o agrupamento da enfermidade se exibe no Quadro 1.

Quadro 1. Informações da dengue.

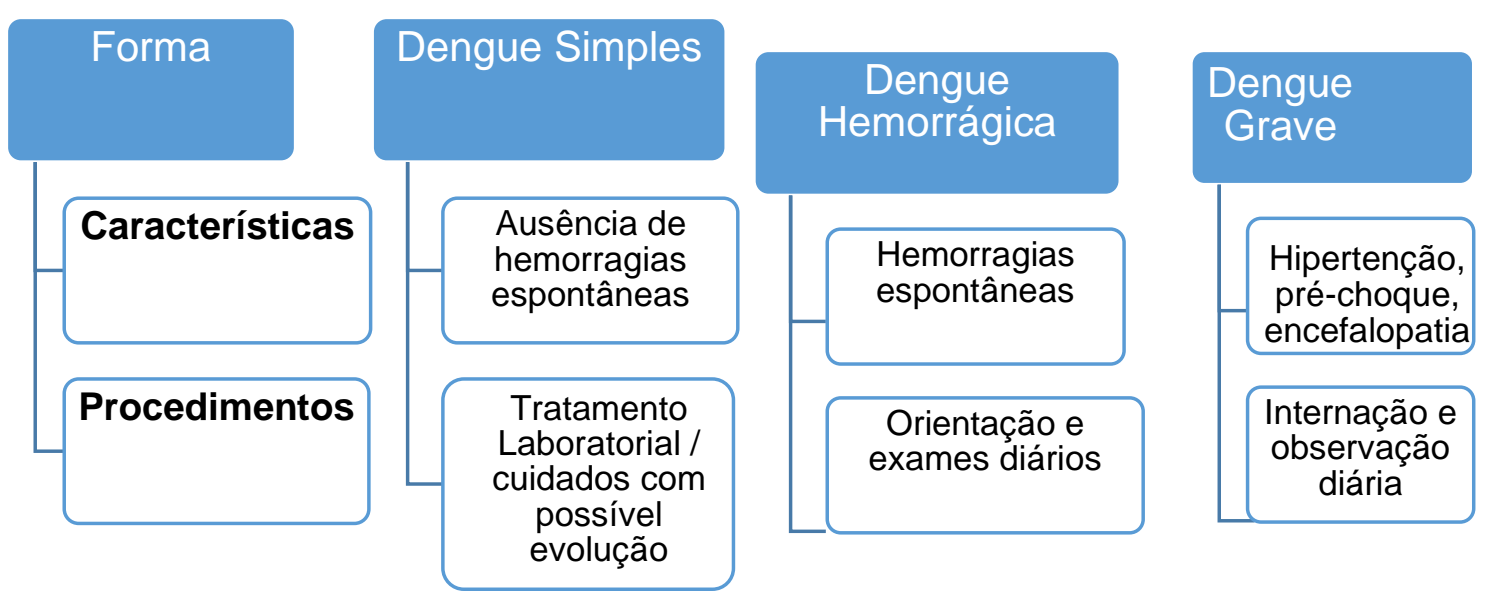

Fonte: Adaptado de Marzochi (1991).

O quadro acima demonstra a configuração da Dengue, relatada pelo Sistema de Saúde do Brasil que divide a dengue em Simples, Hemorrágica e Grave, tais condições atribuídas à doença consistem primordialmente nas particularidades demostradas durante exames laboratoriais de sangue que analisam a contagem das plaquetas e dos glóbulos vermelhos que 
indicam as condições de saúde do paciente com suspeita de dengue. Posteriormente, os procedimentos devem seguir as orientações laboratoriais e realização de exames predeterminados pela equipe médica (OMS, 2019).

O agravante correlacionado ao vírus da dengue consiste no indivíduo que apresenta um quadro de baixa imunidade, associada a uma enfermidade já adquirida anteriormente como a AIDS ou Lúpus, o que leva o paciente a desenvolver uma baixa imunidade, desenvolvendo a dengue grave que pode culminar com a morte do infectado (Figura11).

Figura 11. Morte por dengue.

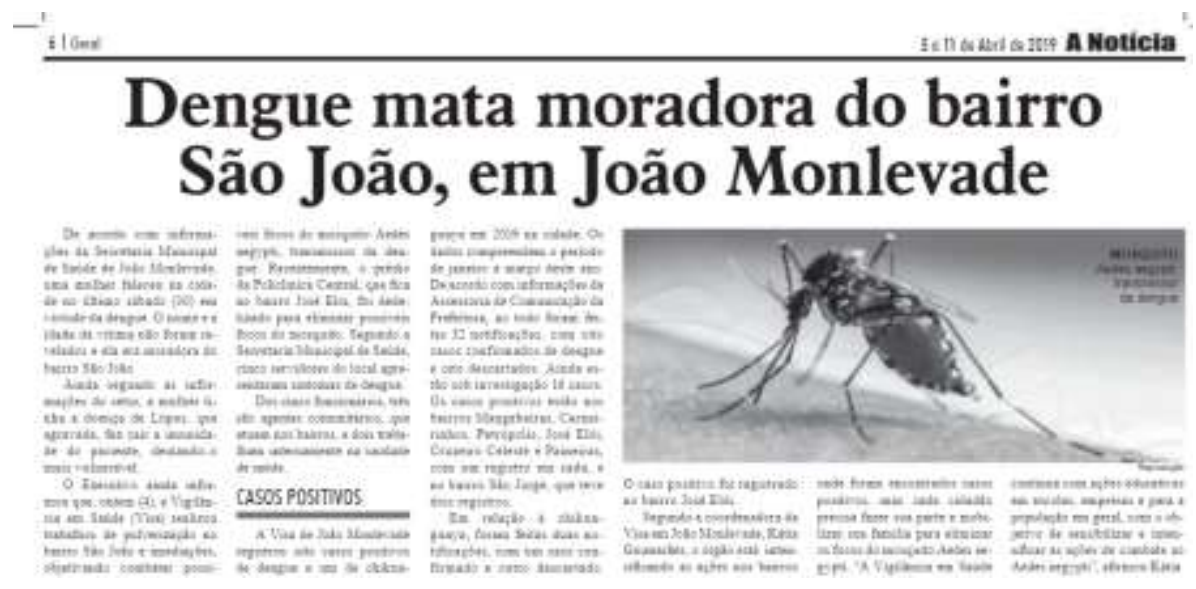

Fonte: Portal de Jornal a Notícia (2019).

\section{Diagnóstico e Tratamento da Dengue}

Devido ao número de casos suspeitos de dengue se intensificarem nas últimas décadas no Brasil, o Ministério da Saúde desenvolveu uma metodologia de diagnóstico e acompanhamento de casos suspeitos de dengue, onde são realizados exames específicos que possam detectar a enfermidade no ser humano. Uma das técnicas de diagnóstico é a prova do laço, que consiste em insuflar o manguito no antebraço do paciente e manter por 3 minutos em crianças e por 5 minutos em adultos ou até o surgimento de petéquias. Após o procedimento é desinsuflado o ar do manguito e delineado um quadrado com $2,5 \mathrm{~cm}$ no local de maior concentração de petéquias, como observado na Figuras 12 A e 12 B.

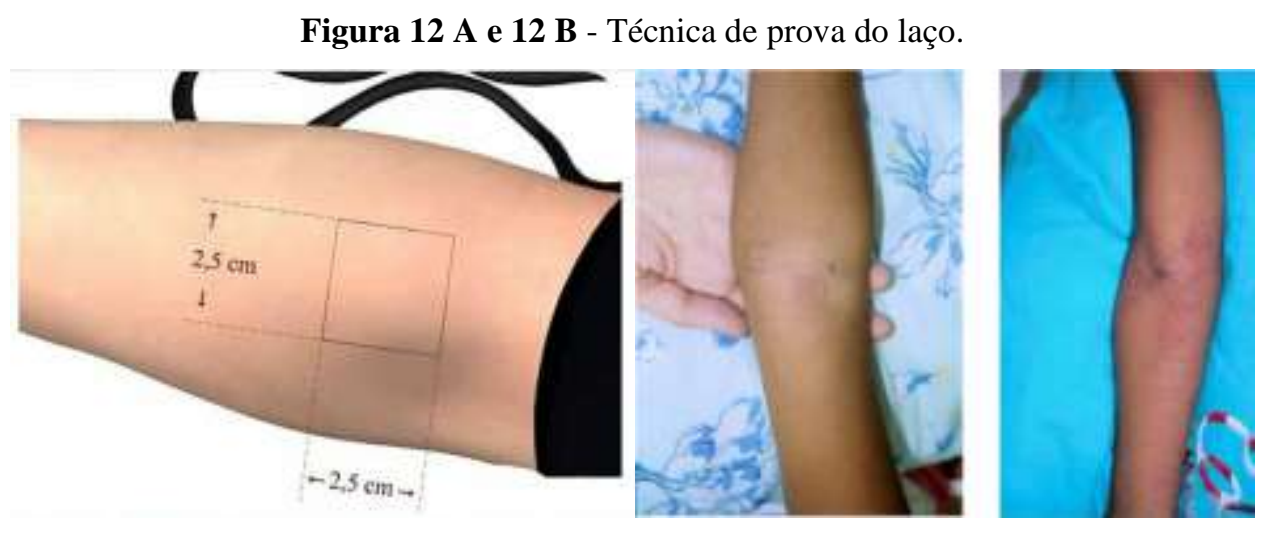

Fonte: OMS (2007).

Segundo o Ministério da Saúde (2000), a prova do laço tem um papel relevante na domada de decisões e na triagem do paciente que possa apresentar sintomas de dengue, pois ele detecta o indicador hemorrágico do grau I de Febre hemorrágica da dengue - FHD, caracterizando a fragilidade capilar do paciente. 
Obtendo a prova do laço positiva ou negativa somado a sintomas específicos da enfermidade, os pacientes são divididos em grupos de procedimento, sendo desenvolvidos diferentes tipos de tratamento, sendo eles A, B, C, D (Brasil/ MS, 2007). As condutas e os exames específicos para cada tipo de tratamento podem ser observados na Figura 13 do fluxograma.

Figura 13- Fluxograma: Classificação de risco e manejo do paciente.

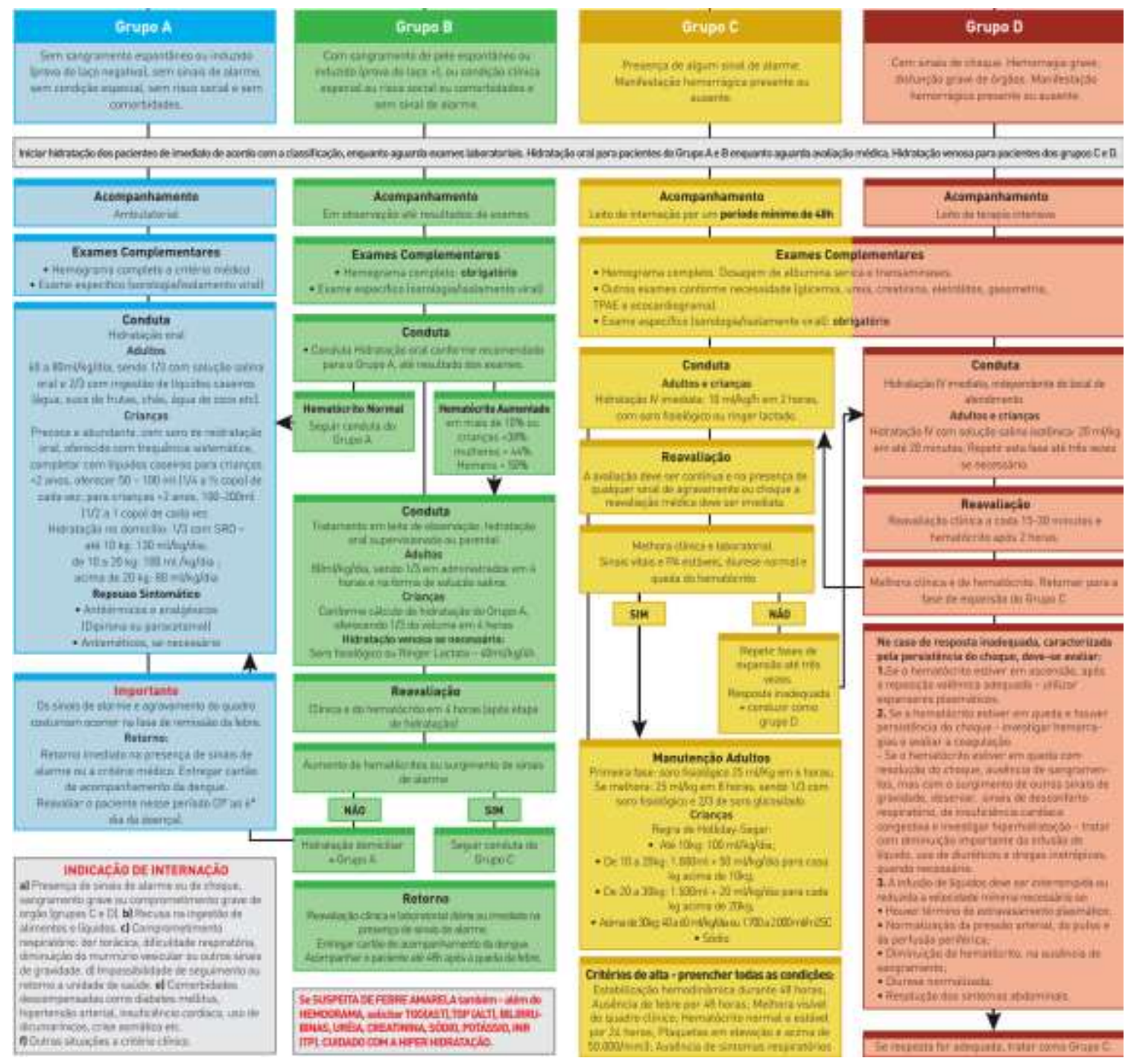

Fonte: Ministério da Saúde (2019).

Percebe-se no fluxograma do Ministério da Saúde procedimentos específicos para todos os grupos afetados pela dengue, como hidratação imediata, acompanhados de avaliação médica e acompanhamentos diferenciados para cada tipo de dengue, que intercalam entre uma avaliação laboratorial ao leito de terapia intensiva. Os exames também possuem perfis diferenciados, cada grupo tem os exames de hemograma e sorologia obrigatórios. No grupo C e D são descritos além destes exames a complementação de diagnóstico por meio dos exames de ureia, glicemia e ecocardiograma, e o isolamento viral é obrigatório nestes grupos. A conduta dos grupos é distinta, a exemplo do uso da hidratação e procedimentos específicos para cada série de pacientes.

\section{Conclusão}

Em vista dos argumentos apresentados compreendemos a importância de analisar as particularidades da dengue, traçando olhares interdisciplinares quanto à gênese do vetor, seus métodos de ação, suas especificações biológicas e 
geográficas. Nesse sentido, cabe ainda a compreensão sobre as características viróticas da enfermidade com o intuito de desenvolver uma sistemática clínica sobre cada sorotipo apresentado, compreendendo seu campo de ação territorial e seus sintomas na população humana, desenvolvendo metodologias para diferentes cenários apresentados.

Destaca-se a relevância de uma análise clínica segura, associada a um hábil atendimento com o propósito de assegurar um diagnóstico eficiente, amparado em procedimentos técnicos, pré-estabelecidos pelos órgãos competentes no campo da patologia endêmica. Em conformidade com o diagnóstico hábil e efetivo, os órgãos governamentais através de pesquisas e um corpo técnico interdisciplinar oferecem uma metodologia de ação, sobre cada grupo epidêmico, estabelecendo um código de conduta heterogênico, com prescrições clínicas e fármaco adequado a cada perfil e intervenções clínicas posteriores.

Sugere-se para estudos posteriores, que sejam avaliados quantitativamente os dados relacionados ao crescimento da dengue no Brasil, bem como o avanço nas técnicas de controle de seus vetores.

\section{Referências}

ABNT. (2016). NBR6023: informação e documentação: referências bibliográficas: elaboração. Rio de Janeiro: Associação Brasileira de Normas Técnicas $(\mathrm{ABNT})$

Barreto, M. L., \& Teixeira, M. G. (2008). Dengue no Brasil: situação epidemiológica e contribuições para uma agenda de pesquisa. Estudos avançados, 22, 53-72.

Brasil. (2007). Ministério da Saúde. Secretaria de Vigilância em Saúde. Diretoria Técnica de Gestão. Dengue: diagnóstico e manejo clínico - Adulto e Criança. Ministério da Saúde, Secretaria de Vigilância em Saúde, Diretoria Técnica de Gestão. (3a ed.), Ministério da Saúde, 28 p. (Série A. Normas e Manuais Técnicos)

Brasil. (2001). Plano Nacional de controle da dengue. Ministério da Saúde, Fundação Nacional de Saúde.

BRASIL. (2012). Plano Nacional de controle da dengue. Ministério da Saúde, Fundação Nacional de Saúde.

Catão, R. C. (2012). Dengue no Brasil: abordagem geográfica na escala nacional. Cultura Acadêmica, UNESP. Caseiro, M. M.et al. (2019). Dengue. http://www.moreirajr.com.br/revistas.asp?fase=r003\&id_materia=2399

Caseiro, M. M.et al. Dengue. (2019) <http://www.moreirajr.com.br/revistas.asp?fase=r003\&id_materia=2399>

FIOCRUZ, (2008). Vetor da dengue na Ásia, A. albopictus é alvo de estudos. IOC notícias. http://www.fiocruz.br/ioc/cgi/cgilua.exe/sys/star t.htm?infoid=576\&sid=32, Acesso em 03 julho. 2019.

Floriano, S. (2018). Influência da pluviosidade, temperatura ambiente e diversidade de criadouros no desenvolvimento de aedes aegypti (linnaeus 1762) e aedes albopictus (skuse 1894) em três municípios do sul de Santa Catarina.

Funasa. (2001). Dengue: Instruções para pessoal de combate ao vetor.

Lopes, N., Nozawa, C., \& Linhares, R. E. C. (2014). Características gerais e epidemiologia dos arbovírus emergentes no Brasil. Revista Pan-Amazônica de Saúde, 5(3), 10-10.

Martins, L. G. de L., Mourão, K. Q., Pimentel, I. M. de S., Panzetti, T. M. N., Ferreira, I. P., Coelho, L. A. C., Boulhosa , M. F., Carvalho, D. S. de., Gomes, V. R., Cordovil, A. B. C., Silva , L. da S. E., Ribeiro, G. M., Mata, M. G. da., Tavares, I. I. S., Oliveira, R. B. S. de., Silva, C. de M. da., Silva, L. C. M. da., Ferreira, F. dos S., Silva, F. M. da., \& Pinto, J. V. C. (2021). Nursing care for a patient with non-organic and non-specific psychosis: report of academic experience. Research, Society and Development, 10(2), e8810212274. https://doi.org/10.33448/rsd-v10i2.12274.

MS. Ministério da Saúde. Secretaria de Vigilância em Saúde. Informe Epidemiológico da Dengue, Análise de situação e tendências 2010. http://www.dengue.org.br/informe_da_dengue_2010.pdf.

MS. (2012). Portal da Saúde. <http://portalsaude.saude.gov.br/portalsaude/noticia/8309/785/melhoria-na-assistencia-reduz-casos-graves-e-mortes-pordengue.html>

MS. (2008). Diretrizes técnicas. (2a ed.), Ministério da saúde. Secretaria Vigilância em saúde. Departamento de Vigilância Epidemiológica.

OMS. Organização Mundial de Saúde. Prevention and Control of Dengue and Dengue Haemorraghic Fever: comprehensive guidelines. Nova deli: Regional office for south-east asia World Health organization. 1999.

Planeta Invertebrados. (2021). http://www.planetainvertebrados.com.br/index.asp?pagina=artigos_ver\&com=1\&id=119\&local=2 .

Rezende, R. B. (2021). Análise epidemiológica das arboviroses emergentes e reemergentes no Brasil entre os anos de 2019 e 2020. Research, Society and Development, 10(2), e33010212611. https://doi.org/10.33448/rsd-v10i2.12611

Samuel, G. H., Adelman, Z. N., Myles, K. M. (2016). Temperature-dependent effects on the replication and transmission of arthropod-borne viruses in their insect hosts. Curr Opin Insect Sci. 16:108-113. 10.1016/j.cois.2016.06.005 
Research, Society and Development, v. 10, n. 10, e289101018733, 2021

(CC BY 4.0) | ISSN 2525-3409 | DOI: http://dx.doi.org/10.33448/rsd-v10i10.18733

Singhi, S., Kissoon, N., \& Bansal, A. (2007). Dengue e dengue hemorrágico: aspectos do manejo na unidade de terapia intensiva. Jornal de Pediatria, 83, S22S35.

Viana, D. V., \& Ignotti, E. (2013). A ocorrência da dengue e variações meteorológicas no Brasil: revisão sistemática. Revista Brasileira de Epidemiologia, 16, $240-256$.

World Health Organization. Dengue net. <http://www.who.int/globalatlas /DataQuery/default.asp>. 